A report of a subcommittee to the Basic Energy Sciences Advisory Committee

\title{
SCIENCE FOR ENERGY TECHNOLOGY:
} STRENGTHENING THE LINK BETWEEN BASIC RESEARCH AND INDUSTRY

April 2010 


\section{About the Department of Energy's Basic Energy Sciences Program}

Basic Energy Sciences (BES) supports fundamental research to understand, predict, and ultimately control matter and energy at the electronic, atomic, and molecular levels. This research provides the foundations for new energy technologies and supports DOE missions in energy, environment, and national security. The BES program also plans, constructs, and operates major scientific user facilities to serve researchers from universities, national laboratories, and private institutions.

\section{About the "Basic Research Needs" Report Series}

Over the past eight years, the Basic Energy Sciences Advisory Committee (BESAC) and BES have engaged thousands of scientists from academia, national laboratories, and industry from around the world to study the current status, limiting factors, and specific fundamental scientific bottlenecks blocking the widespread implementation of alternate energy technologies. The reports from the foundational Basic Research Needs to Assure a Secure Energy Future workshop, the following ten "Basic Research Needs" workshops, the panel on Grand Challenge science, and the summary report New Science for a Secure and Sustainable Energy Future detail the key basic research needed to create sustainable, low carbon energy technologies of the future. These reports have become standard references in the scientific community and have helped shape the strategic directions of the BES-funded programs. (http://www.sc.doe.gov/bes/reports/list.html)

1 Science for Energy Technology: Strengthening the Link between Basic Research and Industry

2 New Science for a Secure and Sustainable Energy Future

3 Directing Matter and Energy: Five Challenges for Science and the Imagination

4 Basic Research Needs for Materials under Extreme Environments

5 Basic Research Needs: Catalysis for Energy

6 Basic Research Needs for Electrical Energy Storage

7 Basic Research Needs for Geosciences: Facilitating 21st Century Energy Systems

8 Basic Research Needs for Clean and Efficient Combustion of 21st Century Transportation Fuels

9 Basic Research Needs for Advanced Nuclear Energy Systems

10 Basic Research Needs for Solid-State Lighting

11 Basic Research Needs for Superconductivity

12 Basic Research Needs for Solar Energy Utilization

13 Basic Research Needs for the Hydrogen Economy

14 Basic Research Needs To Assure A Secure Energy Future

\section{About this Report}

On January 18-21, 2010, approximately 100 experts representing a broad cross-section from industry, national labs, and academia came together at a BESAC-sponsored workshop to identify basic science efforts and Priority Research Directions for accelerating the development and growth of clean energy technology (see page 15 for the topical areas and Priority Research Directions from the workshop). Particular attention was given to identifying industry needs and the impact of basic science, of the type addressed by DOE's Office of Basic Energy Sciences $(B E S)$, in resolving the show-stoppers to industry progress.

\section{On the Cover}

Emission pattern of a photonic crystal, a patterned surface structure extracting light from a semiconductor-based solid state light. The long lifetime (10 years or more) and high efficiency (expected to reach $50 \%$ or more) of solid state lights makes them attractive replacements for conventional incandescent ( $5 \%$ efficient) and fluorescent ( $20 \%$ efficient) bulbs. Photonic crystals are one approach for directing extracted light away from the semiconductor source, producing 50\% more light emission than would otherwise be obtained. Innovations such as photonic crystals for solid state lighting rely on basic science for their inspiration, implementation, and control. Figure courtesy of J. Simmons, Sandia National Laboratories. 


\title{
Science for Energy Technology: Strengthening the Link between Basic Research and Industry
}

\author{
A Report from the \\ Basic Energy Sciences Advisory Committee
}

Chair:

John C. Hemminger

University of California, Irvine

U.S. Department of Energy

April 2010

\author{
Prepared by the BESAC Subcommittee on \\ Science for Energy Technology \\ Co-chairs: \\ George Crabtree \\ Argonne National Laboratory \\ and \\ Alexis Malozemoff \\ American Superconductor Corporation
}




\section{Basic Energy Sciences Advisory Committee}

Chair:

John C. Hemminger (University of California-Irvine)

Simon Bare (UOP LLC)

Nora Berrah (Western Michigan University)

Sylvia Ceyer (Massachusetts Institute of Technology)

Sue Clark (Washington State University)

Peter Cummings (Vanderbilt University)

Frank DiSalvo (Cornell University)

Mostafa El-Sayed (Georgia Institute of Technology)

George Flynn (Columbia University)

Bruce Gates (University of California-Davis)

Laura Greene (University of Illinois at Urbana-Champaign)

Sharon Hammes-Schiffer (Pennsylvania State University)

Bruce Kay (Pacific Northwest National Laboratory)

Kate Kirby (American Physical Society)

William McCurdy, Jr. (University of California-Davis and Lawrence Berkeley National Laboratory)

Daniel Morse (University of California-Santa Barbara)

Martin Moskovits (University of California-Santa Barbara)

John Richards (California Institute of Technology)

John Spence (Arizona State University)

Kathleen Taylor (General Motors, retired)

Douglas Tobias (University of California, Irvine)

John Tranquada (Brookhaven National Laboratory)

Designated Federal Officer:

Harriet Kung

Associate Director of Science for Basic Energy Sciences 


\section{Subcommittee on}

\section{Science for Energy Technology}

Co-chairs:

George Crabtree (Argonne National Laboratory)

Alexis Malozemoff (American Superconductor Corporation)

Simon Bare (UOP LLC)*

Kurt Edsinger (Electric Power Research Institute)

Richard Esposito (Southern Company)

Charles Gay (Applied Materials, Inc.)

Lori Greene (University of California-Irvine)

John C. Hemminger (ex-offico, University of California-Irvine)**

Marc Kastner (Massachussetts Institute of Technology)

Bernd Keller (Cree)

Patrick Looney (Brookhaven National Laboratory)

Celia Merzbacher (Semiconductor Research Corporation)

Omkaram Nalamasu (Applied Materials, Inc.)

Gregory Powers (Verenium)

Bart Riley (A123 Systems)

John Sarrao (Los Alamos National Laboratory)

Thomas Schneider (National Renewable Energy Laboratory)

* BESAC Member

**BESAC Chair 


\section{Table of Contents}

Executive Summary

The Energy Innovation Challenge

Seizing the Opportunity

$\begin{array}{ll}\text { Priority Research Directions } & 7\end{array}$

$\begin{array}{ll}\text { Overarching Themes } & 7\end{array}$

$\begin{array}{ll}\text { Crosscutting Areas of Scientific Expertise } & 7\end{array}$

$\begin{array}{lr}\text { Barriers and Solutions } & 9\end{array}$

Communication 9

$\begin{array}{ll}\text { Collaboration } & 10\end{array}$

Workforce Development 10

$\begin{array}{ll}\text { User Facilities } & 12\end{array}$

$\begin{array}{lr}\text { Conclusions and Recommendations } & 14\end{array}$

Sidebars

The Energy Science and Technology Spectrum 2

Studying Commercial Batteries in Action at a BES User Facility 6

Flexible Electronics-A New Route to Printed Photovoltaics 8

Basic Research in Combustion Impacts Commercial

Engine Design $\quad 11$

BES-Funded Scientific User Facilities $\quad 13$ Priority Research Directions from BESAC Workshop
$\quad$ on Science for Energy Technology 


\section{Executive Summary}

The nation faces two severe challenges that will determine our prosperity for decades to come: assuring clean, secure, and sustainable energy to power our world, and establishing a new foundation for enduring economic and jobs growth. These challenges are linked: the global demand for clean sustainable energy is an unprecedented economic opportunity for creating jobs and exporting energy technology to the developing and developed world. But achieving the tremendous potential of clean energy technology is not easy. In contrast to traditional fossil fuel-based technologies, clean energy technologies are in their infancy, operating far below their potential, with many scientific and technological challenges to overcome.

Industry is ultimately the agent for commercializing clean energy technology and for reestablishing the foundation for our economic and jobs growth. For industry to succeed in these challenges, it must overcome many roadblocks and continuously innovate new generations of renewable, sustainable, and low-carbon energy technologies such as solar energy, carbon sequestration, nuclear energy, electricity delivery and efficiency, solid state lighting, batteries and biofuels. The roadblocks to higher performing clean energy technology are not just challenges of engineering design but are also limited by scientific understanding. Innovation relies on contributions from basic research to bridge major gaps in our understanding of the phenomena that limit efficiency, performance, or lifetime of the materials or chemistries of these sustainable energy technologies. Thus, efforts aimed at understanding the scientific issues behind performance limitations can have a real and immediate impact on cost, reliability, and performance of technology, and ultimately a transformative impact on our economy.

With its broad research base and unique scientific user facilities, the DOE Office of Basic Energy Sciences (BES) is ideally positioned to address these needs. BES has laid out a broad view of the basic and grand challenge science needs for the development of future clean energy technologies in a series of comprehensive "Basic Research Needs" workshops and reports (inside front cover and http://www.sc.doe.gov/bes/reports/list.html) and has structured its programs and launched initiatives to address the challenges.

The basic science needs of industry, however, are often more narrowly focused on solving specific nearer-term roadblocks to progress in existing and emerging clean energy technologies. To better define these issues and identify specific barriers to progress, the Basic Energy Sciences Advisory Committee (BESAC) sponsored the Workshop on Science for Energy Technology, January 18-21, 2010. A wide cross-section of scientists and engineers from industry, universities, and national laboratories delineated the basic science Priority Research Directions most urgently needed to address the roadblocks and accelerate the innovation of clean energy technologies. These Priority Research Directions address the scientific understanding underlying performance limitations in existing but still immature technologies. Resolving these performance limitations can dramatically improve the commercial penetration of clean energy technologies.

A key conclusion of the Workshop is that in addition to the decadal challenges defined in the "Basic Research Needs" reports, specific research directions addressing industry roadblocks are ripe for further emphasis. Another key conclusion is that identifying and focusing on specific scientific challenges and translating the results to industry requires more direct feedback and communication and collaboration between industrial and BES-supported scientists. BES-supported scientists need to be better informed of the detailed scientific issues facing industry, and industry more aware of BES capabilities and how to utilize them. An important capability is the suite of BES scientific user facilities, which are seen as playing a key role in advancing the science of clean energy technology.

Working together, industry and BES-supported scientists can achieve the required understanding and control of the performance limitations of clean energy technology, accelerate innovation in its development, and help build the workforce needed to implement the growing clean energy economy. 


\section{The Energy Science and Technology Spectrum}

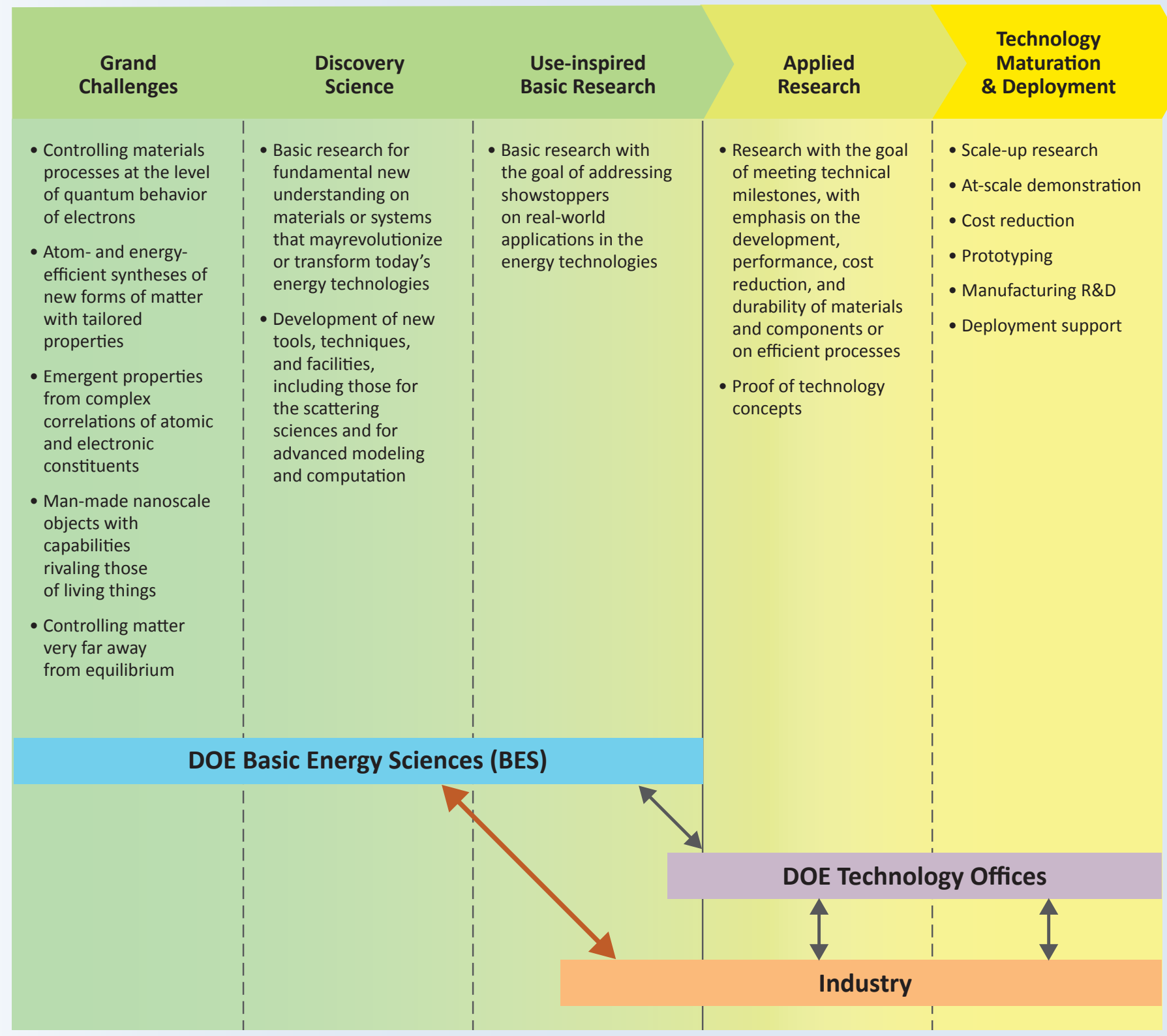

To accelerate the innovation and development of critically needed energy solutions, effective communication is essential between, on one side, fundamental research developed in the DOE Office of Basic Energy Sciences and, on the other side, the applied community, in the DOE technology offices and in industry. Major opportunities exist to enhance the direct link between BES and industry (red arrow). 


\section{The Energy Innovation Challenge}

"The Stone Age did not end because the world ran out of stones. Nor will the oil age end because we have run out of oil1." Indeed, the stone age ended because humans discovered bronze, a material with more desirable properties and greater functionality than stone. So too, our dependence on fossil fuels, including oil, will end when human innovation finds alternative sources of energy that are more desirable, functional, and cost-effective than fossil fuels.

Today, it is clear that the way the United States uses energy to power its cars, heat its homes, and generate and use electricity is not sustainable and must change dramatically and rapidly in the first decades of the 21st century. We must limit the economic and national security consequences of the coming peak in world oil production, find alternatives to imported oil, and limit the climate impacts of our dominant use of fossil fuels.

Remarkably, the United States imports 50\% more oil today than it did in $1979^{2}$, while our own production and proven reserves have declined by $30 \% 3,4$. Imported oil transferred in excess of $\$ 330 \mathrm{~B}$ in 2008 from the U. S. economy to foreign producers 5 , about half of that year's national trade deficit ${ }^{6}$ and a major drain on economic recovery. Over this same period, 1979-2008, the U.S. consumption of coal doubled 7 , and today $86 \%$ of our primary energy consumption depends on fossil fuel combustion ${ }^{8}$. Current estimates are that by 2050 , and without major innovations, U. S. consumption of primary energy will grow by $\sim 23 \%$ and the global consumption will grow by $70 \%$, and the majority of the energy will come from fossil fuels ${ }^{9}$.

Beyond our energy challenges, we face pressing economic challenges, to build a new foundation for enduring jobs and economic growth. Clean energy technologies offer an unprecedented opportunity to launch a new cycle of innovation and high volume exports that will re-establish the nation's economic foundation. Clean energy technology is an untapped economic engine, equivalent in size and reach to automobile technology in the 20th century.

But the United States may be falling behind. In 2009, China vaulted past Denmark, Germany, Spain, and the United States to become the world's largest producer of wind turbines. In the last two years, China has surpassed the West to become the world's largest manufacturer of solar panels, and China is among the leaders in developing new nuclear power systems. This raises the uncomfortable question: will the U.S. trade its dependence on foreign suppliers of oil for a dependence on foreign suppliers of clean energy technology?

Meeting the energy needs of the nation and the world is an enormous challenge. Expansion of existing carbonintensive energy resources is not the solution. A host of new technologies is needed to provide renewable, sustainable, and low carbon energy-technologies that are robust and cost-competitive with existing fossil fuelbased approaches. There is no "silver bullet" that will solve the energy challenge in a single stroke. Instead, we must develop a variety of new clean energy technologies that address both the energy supply and how we utilize energy. These include solar and wind energy, carbon sequestration, advanced nuclear energy, enhanced electricity delivery and efficiency, electrified transportation, solid state lighting, batteries and biofuels. In this report, we refer to these new technologies as "clean energy technologies."

A surge of innovation is needed to propel these technologies to their full transformative potential. These technologies are in their infancy, like the steam engine in James Watt's day. Clean energy technologies perform far below their potential, not for lack of engineering effort, but often for lack of basic understanding of the phenomena, materials, and chemistry that govern their operation or limit their performance. The steam engine and combustion energy technology blossomed when we mastered the science of thermodynamics, and clean energy technologies will boom as we understand the basic principles underlying their operation.

At its heart, the concept of "innovation" refers to new ideas and discoveries that change the course of a technology. Some innovations, such as the laser and fiber optics, or the transistor, are "disruptive;" dislocating a prevailing technology, such as bundles of copper wire previously used for communications, or the vacuum tube previously used for computation and communications. 
But most innovations are more incremental in nature, each addressing shortcomings in existing technologies or improving the performance, largely without fundamentally changing the technology itself. Thus, technological progress is more than a series of supernovae or spectacular discoveries of completely novel materials and processes. Rather, it is often based on sustained efforts of testing new concepts, identifying roadblocks, and pursuing scientific and technical solutions. It relies on a foundation of scientific knowledge, thereby enabling a technology to steadily advance to the point where it can reach a commercial tipping point and make a truly transformative impact on society; just as generation after generation of innovative advances in silicon technology yielded Moore's law and game-changing breakthroughs in information technology.

Many clean energy technologies today-solar photovoltaics, solid-state lighting, batteries for plug-in vehicles, and high-temperature superconductor wires-are advancing in this way, with both continuous innovation based on scientific understanding coupled with engineering as well the disruptive discoveries that lead to radical changes in energy technologies. In both cases, basic energy research has played, and continues to play a central role in the innovation process.

The United States is fortunate to have a profusion of dynamic companies, both large and small, poised to lead the world in these clean energy technologies, powering a new surge of economic growth. But they require the foundational skills, tools, and techniques of state-ofthe-art science in order to bring these technologies to a commercially competitive level. Therefore, innovation in clean energy relies to a great extent on publicly funded basic research conducted at universities and national laboratories to create the underlying enabling scientific knowledge.

DOE's Office of Basic Energy Sciences (BES) and the Basic Energy Sciences Advisory Committee (BESAC) have laid out the research challenges that need to be overcome to understand the scientific phenomena underlying clean energy technology (see the "Basic Research Needs" reports described on the inside front cover). These reports define the decadal science challenges whose solution will create comprehensive understanding and control of clean energy phenomena.

The needs of industry, however, often focus on nearerterm and much more specific limitations of performance in existing technologies. The limitations can be overcome through targeted basic research efforts aimed at understanding the phenomena underlying performance limitations and contributing innovations based on scientific understanding that remove barriers to technological progress. An interactive effort between BES-supported and industrial researchers, focused on understanding the basic science of performance limitations and translating that knowledge to industry, is a powerful opportunity to accelerate the development and deployment of clean energy technologies.

The link between basic science and industry is critical to achieving the dual goals of assuring our energy security and re-establishing our national foundation for economic and jobs growth. Many examples illustrate the direct impact of BES research on industry (see the sidebars in this report on photovoltaics, batteries, and combustion). However, given the urgency of the challenge and the scope of opportunity, more can and must be done. Seizing this opportunity is the subject of this report.

\footnotetext{
${ }^{1}$ Sheikh Zaki Yamani, Saudi Oil Minister, 1975.

2U.S. crude oil imports: http://www.eia.doe.gov/emeu/aer/txt/ptb0503.html

${ }^{3}$ U.S. oil production: http://tonto.eia.doe.gov/dnav/pet/hist/LeafHandler.ashx?h=pet\&s=mcrfpus1\&f=a

${ }^{4}$ U.S. proven reserves: $h$ ttp://tonto.eia.doe.gov/dnav/pet/hist/LeafHandlerashx?n=PET\&s=RCRR01NUS_1\&f=A

${ }^{5}$ Cost of imported oil: http://www.eia.doe.gov/emeu/aer/pdf/pages/sec5_49.pdf

6U.S. Trade Deficit: http://www.bea.gov/international/bp_web/simple.cfm?anon=484467\&table_id=1\&area_id=3

7U.S. coal consumption: http://www.eia.doe.gov/emeu/aer/pdf/pages/sec7_9.pdf

8U.S. Primary Energy Consumption: http://www.eia.doe.gov/emeu/aer/txt/ptb0103.html

${ }^{9}$ World Energy Consumption: 2006 EIA Annual Energy Outlook http://www.eia.doe.gov/oiaf/ieo/pdf/ieoreftab_1.pdf
} 


\section{Seizing the Opportunity}

On January 18-21, 2010, approximately 100 experts representing a broad cross-section from industry, national laboratories, and academia came together at the BESACsponsored Workshop on Science for Energy Technology to identify key scientific challenges to overcoming technological barriers and to accelerate the innovation of clean energy technologies (see page 15 for the topical areas and Priority Research Directions identified at the workshop). Particular attention was given to identifying industry roadblocks and the impact of basic science in resolving the show-stopping performance limitations. The depth and breadth of industrial participation at the Workshop sends a strong message that industry sees broad value in participating directly in discussions of the fundamental science challenges underlying the clean energy technologies.

Realizing the impact of basic science on clean energy technology requires enhanced partnership between BESfunded scientists and industry. Engagement is needed at the leadership level of industrial and DOE senior management to cultivate a common vocabulary and vision for success, and at the working scientist level to foster novel forms of teaming and collaboration. While Bell Labs and IBM Research are often and appropriately held up as models to emulate for fundamental-applied partnerships, today's reality is much more complicated and promising than the internal success stories of two large companies in the telecommunication and information technology industries. Today's environment includes not just large companies but also a host of dynamic start-up companies at the forefront of technical innovation in energy that need the foundational science BES can provide.

DOE supports a spectrum of research efforts aimed at developing and improving the performance and reducing the cost of clean energy technologies. The relationships among the scientific and engineering efforts supported by DOE within BES, the DOE technology offices, and industry are shown schematically in the sidebar "Energy Science and Technology Spectrum." BES concentrates on the basic science, including use-inspired basic research that addresses the physical phenomena underlying clean energy technologies and real-world application showstoppers; the technology offices on applied research and demonstrations with industry; and industry on applied research and ultimate commercial deployment. The complementary nature of the investments is vitally important to innovation in the energy sector in the United States. Given the key role of scientific understanding in the innovation process, and the relative immaturity of clean energy technologies, BES-funded research is playing a vital role in the development of these technologies. BES investments in basic and grand challenge research, and the development and application of new tools and techniques to probe materials, chemistries, and phenomena are at the heart of new and emerging energy technologies.

Over the course of the last eight years, BES and BESAC have developed a series of eleven "Basic Research Needs" workshops and reports each devoted to a specific aspect of the energy challenge, and all developed with industrial participation (see inside front cover). These reports have become standard references in the community and have helped shape the strategic directions of the BES programs and initiatives. In addition, BES stewards world-leading user facilities including photon and neutron sources, nanoscience research, and electron microscopy centers. These facilities are essential tools in state-of-the-art studies of the complex materials and chemical processes of alternative energy conversion and are utilized by many industrial partners. There are remarkable success stories of industry building on BES research results and user facility capabilities to advance clean energy technology (see sidebars on photovoltaics, batteries. and combustion).

Given the magnitude of our decadal energy challenges and the pressing need for enduring jobs and economic growth, the cycle of innovation in clean energy technologies must be accelerated. To this end, enhanced and direct two-way communication between the BES community and industry is important. Basic and industrial scientists bring different perspectives, whose interplay is critical to stimulating new ideas and approaches for solving critical 
problems. BES and BES-supported scientists need clear understanding of the near-term impediments and challenges faced within industry to inform programmatic decisions and to identify research opportunities. At the same time, industry needs to learn how BES-supported researchers, capabilities, and facilities can help develop the necessary understanding of its technologies to enable innovation of new approaches to higher performance, longer lifetime, and lower cost.

Interaction of complementary capabilities such as industrial state-of-the-art processing and the unique BES user facilities is essential for success. An important factor in successfully developing these interactions will be enhancing industrial access to BES user facilities.
Enhanced communication will arise naturally in the context of the Priority Research Directions identified at this Workshop, which focused specifically on the showstoppers faced by industry. Beyond communication, BESfunded researchers and facilities can extend their active technical collaboration with industry at universities and national laboratories. Such collaboration is essential to advancing the complex, multidisciplinary research that drives clean energy technologies. The Priority Research Directions outlined at the Workshop are particularly desirable opportunities for interactive collaboration. Novel forms of collaboration and partnership must be devised if the full innovation potential inherent in our energy challenge is to be realized.

\section{Studying Commercial Batteries in Action at a BES User Facility}

New batteries based on sodium metal halide chemistry have the potential to store electricity for transportation applications such as hybrid locomotives, buses, and heavy duty vehicles, and also for utility storage for load-leveling on the grid. An in-depth understanding of the complex chemistry of the chargedischarge cycle is critical for achieving enhanced power and energy

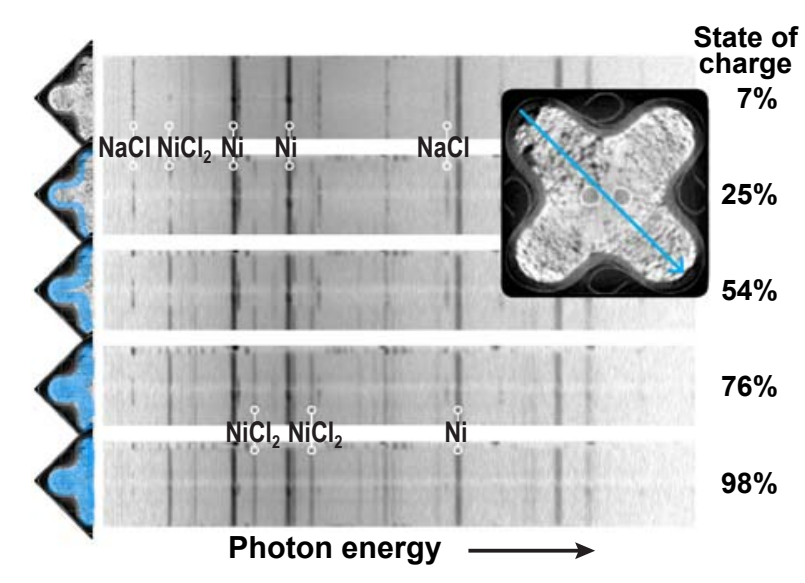

Cross-sectional X-ray diffraction patterns, acquired at NSLS, of GE's sodium metal halide battery cell in operation. The five diffraction pattern strips were taken at various states of charging and show the conversion from $\mathrm{NaCl}$ and $\mathrm{Ni}$ to $\mathrm{Na}$ and $\mathrm{NiCl}_{2}$. The diagonal blue line on the reconstructed neutron tomography image indicates the locations in the cell where the X-ray diffraction data were collected. densities, longer life, and greater safety for the battery, yet the active components are generally inaccessible behind the steel battery housing.

The National Synchrotron Light Source (NSLS) at Brookhaven National Laboratory working with General Electric (GE) and Rutgers University has developed a hard X-ray probe for batteries that can penetrate housings with special X-ray transparent windows and reveal the evolution of microstructure deep within the cell, the mechanisms of charge transport, the nature of the phase changes that take place during electrochemical cycling, and details of the degradation and failure modes of the chargedischarge cycle. Together they have carried out real-time experiments on the processes occurring in commercial prototypes of sodium metal halide batteries designed by GE. Energy dispersive $X$-ray diffraction (EDXRD) using the synchrotron radiation light source achieves 4-D maps of the internal electrochemistry of the battery: three spatial dimensions plus the time evolution of the charge-state of the electrodes. EDXRD measurements reveal local electrochemical kinetics in unprecedented levels of detail deep inside commercial-size batteries, enabling direct feedback into the battery design optimization process, and helping to validate and inform theoretical models.

GE has recently announced that it will take the sodium metal halide battery into production at a $\$ 100$ million manufacturing facility in upstate New York. The ongoing collaboration between GE and the NSLS began in June 2009 after NSLS sponsored the "Energy Storage Research Opportunities at the National Synchrotron Light Source" workshop. 


\section{Priority Research Directions}

At the Science for Energy Technology Workshop, participants identified 26 Priority Research Directions (PRDs) central to near-term energy technology challenges. These are listed on page 15, and they span the full range of energy technologies considered. Many of these PRDs echo those identified earlier in BES-sponsored "Basic Research Needs" (BRN) workshops and reports (see inside front cover and www.sc.doe.gov/production/bes/reports/list. html). However, some of the Workshop research directions were entirely new, and most were directed to developing scientific understanding underlying performance limitations in emerging clean energy technologies rather than on the longer-term search for entirely new materials or processes.

For example, gallium-nitride based solid-state lighting materials already developed by industry show remarkably high efficiencies of over $50 \%$, as compared to the $5 \%-20 \%$ efficiencies of standard incandescent and fluorescent lighting. Since lighting constitutes over $20 \%$ of our use of electrical energy, broad use of solid state lighting would have a truly transformative impact on our energy efficiency. However, this high efficiency degrades when the materials are driven to the level required for large area lighting. While there are many theories, we lack a predictive understanding of this "droop" phenomenon which could enable solutions and propel the technology to widespread use. Droop is one of the Priority Research Directions identified at the Workshop.

BES's broad commitment to fundamental research includes not only grand challenge and discovery science, but also use-inspired basic research needed to address the underlying causes of performance-limiting phenomena such as droop. A key recommendation of this report is that BES seek opportunities to enhance existing mechanisms and develop new mechanisms to strengthen useinspired research of interest to industry by addressing the Priority Research Directions identified in this report.

\section{Overarching Themes}

Several overarching themes, in addition to technologyspecific roadblocks, emerge from the Priority Research Directions.
1. Research to develop foundational scientific understanding of at-scale production challenges in existing materials and processes for emergent energy technologies.

e.g., Understanding loss processes that limit efficiency of full-scale solar cells by as much as a factor of two compared to laboratory cells: success could vault photovoltaic technology into cost-performance parity with fossil-fuel-based electric energy, enabling a vastly increased solar contribution to renewable energy and opening immense economic opportunities to export inexpensive solar technology to the world.

2. Research that extends beyond empiricism towards the fundamental understanding of lifetime prediction of materials in extreme environments, especially aging, degradation, and failure.

e.g., Understanding degradation mechanisms under the extreme irradiation, thermal, and corrosive conditions of nuclear reactors: success would enable improved prediction and extended lifetime certifications for existing and future reactors, a critically important source for carbon-free baseload energy complementing the more variable renewable resources like solar and wind.

3. Research aimed at the discovery of specific new materials or chemical processes with targeted functionality that would lower the cost and improve the efficiency of clean energy technologies.

e.g., Developing modeling frameworks to predict performance of new biomass conversion catalysts in complex cellulosic mixtures: success would enable a breakthrough in conversion of cellulosic biomass to fuels, supplementing or even displacing the present corn-to-ethanol pathway and significantly reducing demand for oil.

\section{Crosscutting Areas of Scientific Expertise}

In addition to these common overarching themes, the Priority Research Directions revealed crosscutting areas of scientific expertise required for success. 


\section{Flexible Electronics- Printed Photovoltaics for Solar Energy}

Continuing since 2003, BES-funded research at the University of Illinois at Urbana-Champaign led to the development of printable single crystal semiconductors for a new type of photovoltaic system for better performance and lower cost renewable solar energy. Exploiting basic materials growth and etching techniques combined with principles of soft adhesion in viscoelastic materials, the team established methods for micro-transfer 'printing' of inorganic semiconductors such as $\mathrm{Si}$ and $\mathrm{GaAs}$ onto diverse substrates, including sheets of plastic and slabs of rubber. Such hybrid 'hard/ soft' integrated systems provide mechanical properties previously thought to be impossible with inorganics, such as extremely high flexibility and even fully elastic responses to large strain deformations. The figure shows a flexible monocrystalline silicon solar module that consists of an interconnected array of hundreds of microscale-printed cells.

These basic research successes led to the launch of a startup company, Semprius Corporation, and to funding by the DOE Office of Energy Efficiency and Renewable Energy (EERE) Photovoltaic Technology Incubator and Next Generation Photovoltaic Devices and Processes programs. The immediate goal is to commercialize a new type of high concentration photovoltaic device that combines the novel printing technology using GaAs microcells with microlens optics. The result would be a low profile, lightweight module that achieves better performance and lower cost than other solar technologies.

Collaboration between the University of Illinois and Semprius Corporation continues to address the basic science road-blocks to printed solar cells. Other major U.S. companies that are currently developing applications from this BES-funded materials research include Applied Materials, Lockheed Martin, Boeing, Carl Zeiss, Hewlett Packard, Raytheon, Kodak, and Sumitomo.

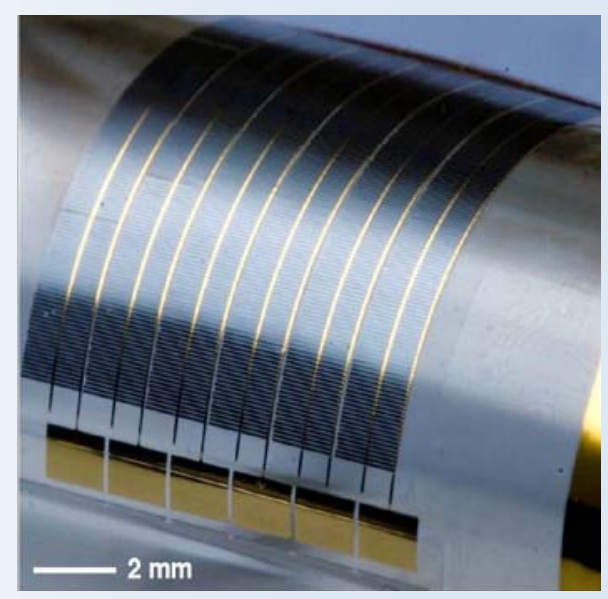

Image of a flexible photovoltaic module composed of an interconnected array of hundreds of monocrystalline silicon microcells. This technology combines the attractive mechanical properties of organic devices with the lifetime and performance possible with inorganics.
The challenge of creating new materials by design, with specific properties or functionalities is ubiquitous. We need to use the enormously powerful computational capability now available to predict the properties of materials with complex atomic and nanoscale structures, so that we can design the structures with targeted functionality needed for a given energy technology. Part of this challenge is to model the properties on all length scales from nanometers to whatever macroscopic-length scale is relevant for the particular technology. We then need to use directed synthesis and fabrication techniques to create the material with the predicted atomic, molecular, and microstructure, and test its functionality in applications using state-of-the-art characterization such as scattering user facilities and benchtop scanning probes. This is especially important and difficult for complex materials with multiple components and interfaces in device geometries.

The understanding and prediction of the role of interfaces was a recurrent theme at the Workshop; advances in surface and interface science, broadly defined, are needed. Interfaces play a critical role in the optical, electrical, mechanical and chemical properties of materials. For example, the efficiencies of solar cells and solid-state lighting are critically sensitive to the behavior of electrons at interfaces between semiconductors with different compositions. The stability of nuclear materials and the movement of $\mathrm{CO}_{2}$ through rock for carbon sequestration depend on the mechanical and chemical properties of surfaces and grain boundaries.

The challenge of understanding and controlling dynamical processes across a wide range of time-scales was also common, calling for expertise in modeling and measuring transport processes and chemical kinetics. For example, one needs to model mass transport and chemical kinetics on time scales from femtoseconds to hours for biofuel production; for carbon sequestration the time scales of importance extend to thousands of years. Many energy conversion phenomena take place far from equilibrium, a prominent theme of previous BES and BESAC workshops and reports.

Put simply, the materials and phenomena that are central to energy technology needs are neither static nor homogenous. Rather, the dynamical processes and intrinsic heterogeneities that dominate complex materials and chemical processes must be understood to enable their most effective utilization. A scientific knowledge base in treating dynamical processes and disorder needs to be brought to bear on clean energy technology. 


\section{Barriers and Solutions}

Recognizing the need to further strengthen the link between basic research and industry and identifying Priority Research Directions that are likely to lead to a near-term impact are only partial steps towards achieving success in research for clean energy technology and accelerating innovation. Workshop participants also identified barriers that have tended to limit progress in the past and suggested practical steps that would accelerate future progress. In particular, opportunities were identified for enhancing communication, fostering collaboration, workforce development, and promoting user facility access.

\section{Communication}

One of the biggest barriers to innovation is insufficient communication and engagement of basic scientists and industry. Communication channels are clouded by differing objectives and operating styles: basic scientists typically set priorities from the "bottom up " (scientific push), following the most compelling scientific opportunities as they arise. They emphasize understanding phenomena and strive to disseminate results quickly through publication. In contrast, industry often sets priorities from the "top down" (technological pull) based on its most critical needs for specific technologies. Industry emphasizes achieving materials and device performance as a higher priority than understanding phenomena, and does not routinely share publicly its internally developed knowledge. Intellectual property and proprietary information issues are an ever-present barrier, even to simple communication.

Despite increased availability of electronic information channels, direct and personal engagement is critical to developing the trust and understanding that leads to effective communication. Communication among BES program managers, BES-supported researchers, and industry is the necessary first step in strengthening ties between basic science and industry. The Workshop provided an opportunity for broad-based engagement between the basic science community and industry to identify problems of common interest in the clean energy arena, to discuss barriers to cooperation, and to consider pathways for going forward. However, a single workshop can only provide a snapshot of energy technology research needs and priorities and conversations of limited technical depth. Solutions will require more sustained and in-depth dialogue to pinpoint the limitations and develop a detailed research agenda to address them. The current research priorities need to be reviewed and updated on a periodic basis, for example through an ongoing series of such workshops. With each cycle, the methodology for obtaining broad input and developing a consensus on priorities can be improved. The Priority Research Directions identified at these workshops can be a valuable and continuing basis for communication between the two communities and a guide for determining new research directions that will have significant impact.

There are many routes to fostering two-way communication in which BES could play a leadership role. BES program managers and BES-funded scientists could reach out to energy industries by attending and presenting at industryoriented conferences, by submitting articles to publications by and for industry, and by establishing relationships with senior officials at industrial professional organizations who can help to communicate BES programs and results to their membership. BES could consider bringing more industry experts into the proposal review process for programs targeting science for clean energy technologies, and it could seek greater industry participation in BESAC. Greater interaction between industry, BES, and its supported scientists will enable more effective identification of opportunities to address the basic research needs of industry. Focused, topical workshops are one possibility. Industry-prepared roadmaps could be useful to inform the science community of basic research needs for the industrial development of clean energy technologies. BES could also explore ways to coordinate the variety of its industrial outreach activities. 


\section{Collaboration}

Beyond enhanced communication, BES, its supported scientists, and industry should seek to actively collaborate on research of mutual interest. Such partnerships leverage the investments of each side, bring to bear their complementary strengths, and ensure strong and sustained engagement by both partners. Partnerships extend the reach of BES programs and accelerate the pace of technology innovations based on scientific understanding. However the obstacles to greater collaboration are even greater than to simple communication, particularly in the area of intellectual property.

Much informal collaboration already exists between BES-funded researchers and individual industry scientists. In addition to these working-level collaborations, more formal activities can take place under agreements that detail the scope of work and intellectual property rights. In some cases industry funds the university or national laboratory research while in others no funds are exchanged and each side funds its own effort. Universities have their own sponsored research agreements and many types of agreements are available for working with DOE labs (http://techtransfer.energy.gov/mechanisms.htm). DOE is presently undertaking a review of its technology transfer policies, with an aim to streamline collaborative research and technology transfer between the laboratories and industry.

Given the fundamental nature of BES-funded research and its value to industry as a whole, BES could consider strategies to engage industry sectors broadly, for example, by working with industry in consortia. Such consortia could identify the common science issues faced by a large segment of industry and communicate them effectively to BES and other basic science organizations. A consortium can link the best and brightest from the basic science and industrial communities-from students and junior scientists to the most senior experts-to tackle hard science problems underlying clean energy technologies and translate basic clean energy phenomena into working technology and large-scale demonstrations. This kind of integration across basic science and technology is a key feature of the Energy Innovation Hubs.

The Energy Frontier Research Centers (EFRCs) provide an existing framework for promoting industry interaction with BES-funded researchers through the industrial collaboration component of their programs and establishment of industry advisory boards (as some have already done).

Another option for encouraging widespread interaction with industry could be university/national laboratory/ industry grants specifically targeting basic science issues on the fertile interface between science and applications. Teams drawn from both communities could pursue the basic science of performance-limiting roadblocks to industrial development of clean energy technologies. The challenges that such grants might support include any of the Priority Research Directions identified here.

Accommodating the differing goals and operating styles of basic researchers and industry is ultimately a matter of sustained commitment and progressive engagement on both sides. As the number and depth of interactions increase, particularly through face-to-face interactions, relationships and understanding that promote trust and more extensive interactions can develop.

Intellectual property is a continuing challenge for basic science-industry collaboration. It is important that scientific research be published openly and widely in high profile journals because disseminating knowledge is a primary objective of the scientific enterprise and is a major form of recognition and career advancement for basic scientists. At the same time, protection of patentable and closely held company information must also be accommodated. This requires that both sides avoid rigid or extreme positions and recognize the other's needs. For example, publication delays to permit filing of patents should be of benefit to all parties. Successful interactions (see sidebars on photovoltaics, batteries, and combustion) demonstrate that this issue can be overcome.

\section{Workforce Development}

Creating a workforce conversant in basic science and clean energy technology that can meet our energy and economic challenges is a major task. Universities must play a leading role in providing curriculum and guidance for the next generation of energy scientists and engineers. BES can play a key role in developing the workforce, by implementing some of the mechanisms for greater communication and collaboration outlined in this report. Workshops, university/national laboratory/industry grants across the basic science - industry 
interface, and collaborative research will promote crosstraining of the existing and next generations of energy researchers that will strengthen the ties between industry and basic science. Industry can make major contributions by establishing fellowships, co-funding university research programs, participating in co-operative programs, providing tuition support, sponsoring conferences and job fairs, and doing its own internal training. With the prospect of rapid growth in the clean energy technology industry, the benefit of such programs will be widely felt.

In addition to funding research and fellowships that will attract faculty and students, BES can take steps to increase the flow of students to careers in the basic science of clean energy technology. The newly established Office of Science graduate student fellowships will help attract top-notch students to the energy field. The university/ national laboratory/industry grants mentioned earlier in this report could support student internships and cooperatives in industry. Such experiences provide an excellent introduction to industrial careers in science and engineering and would establish continuing university-industry relationships that would encourage further interactions.

The talent pool created by BES support of the research priorities and interaction opportunities identified in this report will drive technological innovation based on basic science that can create future clean energy technologies and jobs, as well as new companies.

\section{Basic Research in Combustion Impacts Commercial Engine Design}

The Combustion Research Facility (CRF) at Sandia National Laboratories-California is a unique center for integrating basic and applied research in combustion science and technology. BES operates the CRF as a collaborative laboratory that attracts visiting scientists from academia, national laboratories, and industry from around the world. BES supports vigorous, in-house fundamental research on combustion chemistry, advanced laser diagnostics, and state-of-the-art combustion simulation. The EERE Vehicle Technologies Program supports a complementary program on applied combustion research for internal combustion engines. This, in turn, feeds directly into a wide range of collaborations with industry and industry-supported programs. Examples of the transfer of knowledge between the BES and EERE programs and on to industry are numerous over the CRF's 28-year history.

An important recent example is the achievement of a major milestone in engine design by industry - the first all computationally designed diesel engine by Cummins Inc. The ISB 6.7 liter diesel engine was first marketed in 2007 for the Dodge Ram pickup truck and is manufactured at the Columbus Midrange Engine Plant in Walesboro, Indiana. The combustion system of this engine was designed solely on the basis of computer modeling and analysis, without any prototype testing. Computer design reduced the time and cost of the engine development and led to a more robust, cleaner, and more efficient engine. The laser-diagnostic studies of reacting flows and combustion chemistry and the computational modeling programs supported by BES, combined with the application of these tools supported by EERE, were key enablers for designing this engine. This research provided a comprehensive understanding of the complex turbulent flows and chemistry in diesel combustion, which has been translated to computational models for predicting diesel combustion processes that are now widely used throughout the industry.

Ongoing collaborative research at the CRF is focused on enabling the next generation of clean, high-efficiency internal combustion engines and high-fidelity computational tools for designing these engines. The engines are based on advanced combustion strategies such as homogeneous charge-compression ignition and low-temperature diesel combustion. These strategies offer the potential for ultra-clean combustion and improved

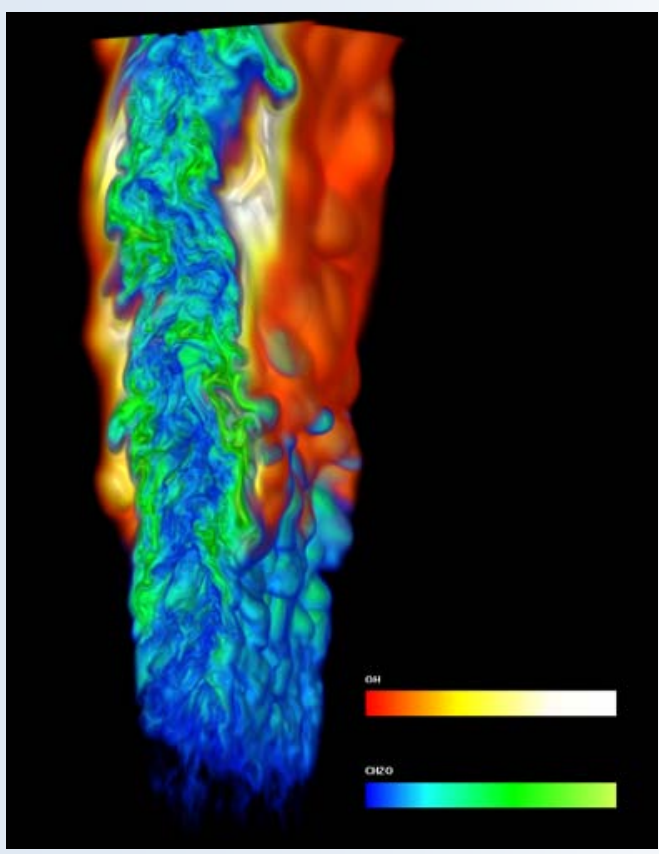

A numerical simulation of an auto-igniting ethylene-air flame showing concentrations of hydroxyl radical and formaldehyde corresponding to the different colors. This stateof-the-art flame simulation, developed under $B E S$ funding, will lead to the next generation of computational models beyond those used for the Cummins ISB 6.7 liter diesel engine. 


\section{User Facilities}

BES supports a suite of complementary user facilities that comprise a unique asset for basic research and industry scientists alike (see sidebar: BES-Funded Scientific User Facilities). These facilities are home to high intensity photon and neutron sources and advanced electron microscopes for measuring composition and structure of materials. Nanoscale science research centers offer state-of-the-art equipment for synthesis and characterization of materials on the scale of atoms and molecules. Using these tools, researchers are able to peer deep inside objects and probe surfaces in ever increasing detail, enabling an understanding of complex materials and chemistry with resolution and sensitivity that is not achievable by any other means. Facilities of this type are well beyond the resources of individual research institutions or companies.

The user facilities are ideally suited to addressing a wide range of science questions with significant technological impact. BES and the user facilities could consider a number of options that would allow the facilities to better serve the industrial user community without deviating from their mission to advance scientific understanding of materials and chemical processes. To the extent possible, it would be desirable to have more uniform procedures for access and use across the various user facilities to expedite coordinated use of multiple facilities by industry and other research organizations. Evaluation of proposals could take into consideration technological impact in addition to scientific merit. Peer review of proposals could include a greater number of industry reviewers. The facilities might consider setting aside a modest fraction of the facility time for "quick response" projects from industry and basic science users. User facility staff researchers could be incentivized and rewarded for assisting nonexpert users from industry, and facilities could increase their outreach to industry by holding workshops to gain greater understanding of industrial needs and barriers to increased participation. These activities are within the technology transfer mission of the laboratories and could significantly enhance the development of clean energy technology.

User facilities could be encouraged to develop and broaden industrial participation. Some possibilities include greater industrial participation on Scientific Advisory Committees, or possibly the development of a separate Industrial Advisory Board. These would help to develop better communications with the facility Director and staff regarding industrial needs for access, as well as new capabilities, instrumentation and beamlines. 


\section{BES-Funded Scientific User Facilities}

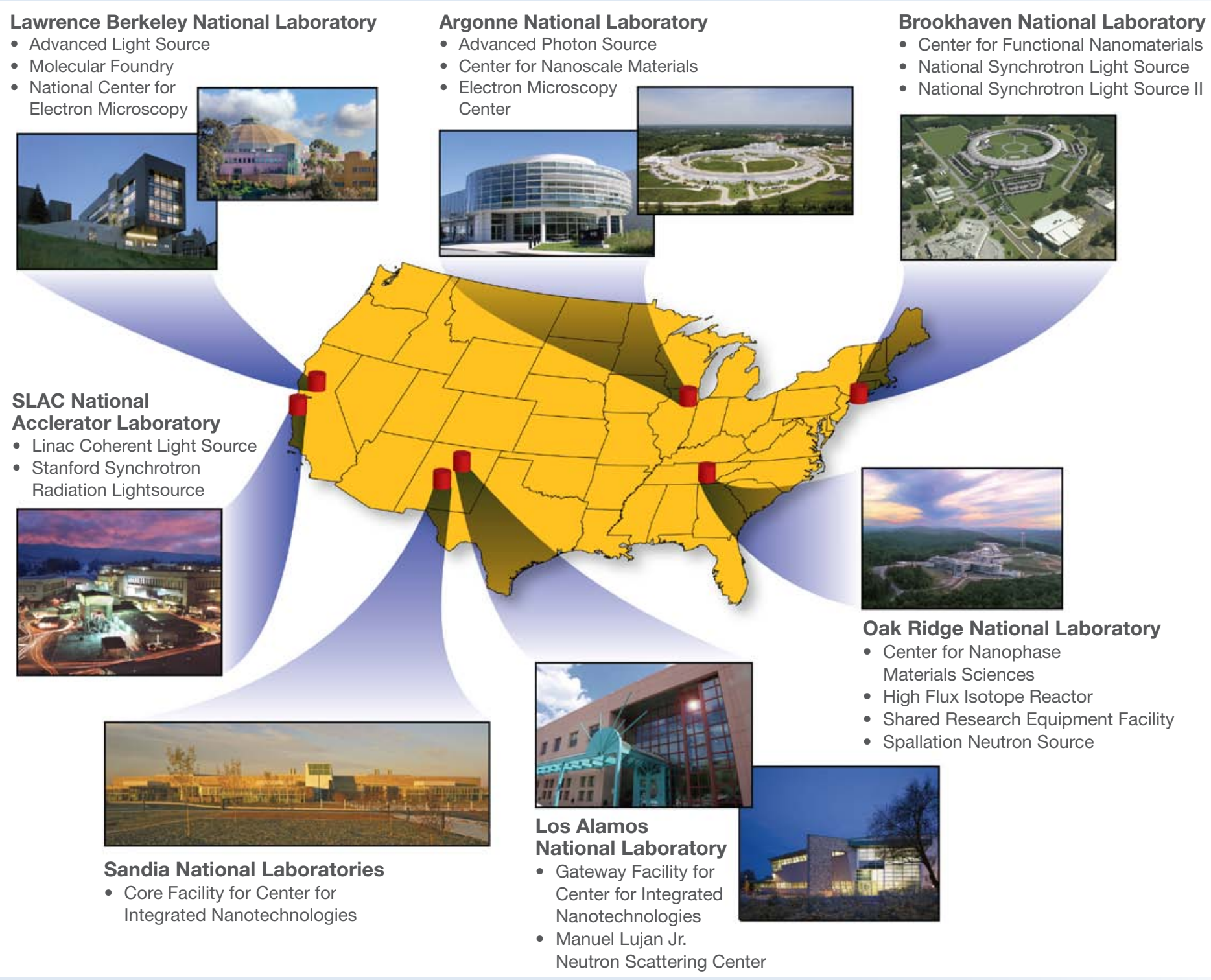




\section{Conclusions and Recommendations}

Many clean energy technologies today-e.g., solar photovoltaics, solid state lighting, batteries for plug-in vehicles, high-temperature superconductor wires-are poised to advance with both continuous innovation based on scientific understanding coupled with engineering, as well as with the disruptive discoveries that lead to radical changes in energy technologies. In both cases, basic energy research has played and continues to play a central role in the innovation process. Basic energy research enables and accelerates the economic and technological transition by revealing the underlying principles controlling clean energy phenomena and translating this knowledge to industry. These innovations can significantly raise the operating performance of clean energy technologies and bring them to the tipping point of competitive viability with traditional fossil technology.

The DOE Office of Basic Energy Sciences (BES), with its broad-based fundamental research program in energy-related science and its unique user facilities, has a leading role in this scientific contribution to our clean energy future. To define the opportunity, the BESAC Workshop on Science for Energy Technology on Jan. 18-21, 2010, brought together a broad cross-section of industry, national laboratory, and academic researchers to delineate the Priority Research Directions that could resolve important technological challenges and to address barriers to effective implementation. The Workshop affirmed the contribution of the "Basic Research Needs " reports in delineating the decadal foundational challenges in the development of alternative energy technologies. A key conclusion of the Workshop is that there are specific scientific issues underlying roadblocks to performance in existing and emerging clean energy industries that could significantly accelerate the innovation process. These were outlined in a set of Priority Research Directions. The second key conclusion was that direct, mutual engagement of BES and BES-funded researchers with industry is critical to achieve greater impact and accelerate the pace of innovation. The link to industry is essential in guiding the use-inspired science of BES-funded researchers, in cultivating interdisciplinary dream teams that include the best and brightest industry and BES-sponsored scientists, and in transferring key insights to industry. Key recommendations are:

- BES's broad commitment to fundamental research includes not only grand challenge and discovery science, but also use-inspired basic research addressing the performance-limiting science challenges identified at the Workshop. BES should seek opportunities to enhance existing mechanisms and develop new mechanisms to strengthen use-inspired research of interest to industry by addressing the Priority Research Directions identified in this report.

- BES and industry should foster stronger communication and more direct technical collaborations between their research communities. This direct engagement of BES-sponsored and industry scientists is essential for focusing basic research attention on key scientific issues that block development of clean energy technologies and for facilitating knowledge transfer to industry.

- BES-supported user facilities should seek to increase the level of industrial participation and use by considering refinements to its access policies, proposal selection criteria, and time allocations to more fully engage industry-based clean energy research; investigating how its existing and proposed beamlines and instrumentation could be adapted to the Priority Research Directions and the needs of industry outlined here; and engaging its beamline scientists and support staff to provide greater assistance to industrial users solving critical challenges in development and deployment of clean energy technologies.

Addressing these opportunities opens enormous opportunities to accelerate transformative solutions to the critical clean energy challenges we face and at the same time to promote the job growth and economic competitiveness we so urgently need for a sustainable and prosperous future. 


\title{
Priority Research Directions from the BESAC Workshop on Science for Energy Technology
}

\author{
Panel 1: Solar Electricity from Photovoltaics, coordinator Charles Gay, Applied Solar \\ Fundamental Properties of Photovoltaic Interfaces \\ Advanced Photovoltaic Analysis and Computational Modeling for Up-scaling \\ Photovoltaic Lifetime and Degradation Science
}

Panel 2: Advanced Nuclear Energy, coordinator Kurt Edsinger, EPRI

Materials Degradation Mechanisms

Advanced Irradiation Effects Scaling

Back End of the Fuel Cycle

Panel 3: Carbon Sequestration, coordinator Richard Esposito, Southern Co.

Extraction of High Resolution Information from Subsurface Imaging and Modeling

Understanding Multi-scale Dynamics of Flow and Plume Migration

Control Science and Tools to Handle Very Slow Rate Processes

Panel 4: Electricity Storage, coordinator Bart Riley, A123 Systems

Materials Development for Enhanced Battery Performance

Novel Device Architecture and Enabling Processes

Understanding and Innovating Heterogeneous Interfaces

Panel 5: Electric Power Grid Technologies, coordinator Thomas Schneider, NREL

High Performance and Reliability Power Electronic Materials

High Temperature Superconductors for the Grid

Insulating Materials with Improved Dielectric and Thermal Properties

New Composite Materials for Low-Sag Overhead Transmission

Panel 6: Advanced Solid State Lighting, coordinator Bernd Keller, Cree

White Light Emission Through Wavelength Conversion

High Efficiency Visible Solid-State Emission at High Current Density and Temperature

Organic Light Emitting Diode Materials and Structures for Reliable, Color-Consistent, High-Luminance Emission

Panel 7: Biofuels, coordinator Gregory Powers, Verenium

Diversity of Biomass and Its Intermediates in Biofuels Processing

Mass Transport Phenomena in Biomass Conversion

Biomass Catalyst Discovery, Characterization and Performance

Panel 8: Efficient Energy Generation and Use, coordinator Om Nalamasu, Applied Materials

Enabling Materials Technologies for Next-Generation Wind Power

Fuel Cell Materials: Understanding and Discovery

Building Technologies and Dynamic Optical and Thermal Properties of Building Envelopes

Panel 9: Scientific User Facilities, coordinator Simon Bare, UOP LLC

Developing Capability and Tools to Support Industry Innovation through User Facilities for:

- "At Scale" Experiments on Commercial Materials/Devices in Real-world Environments

- Development of New Materials

- Study of Interfaces and Interfacial Phenomena 

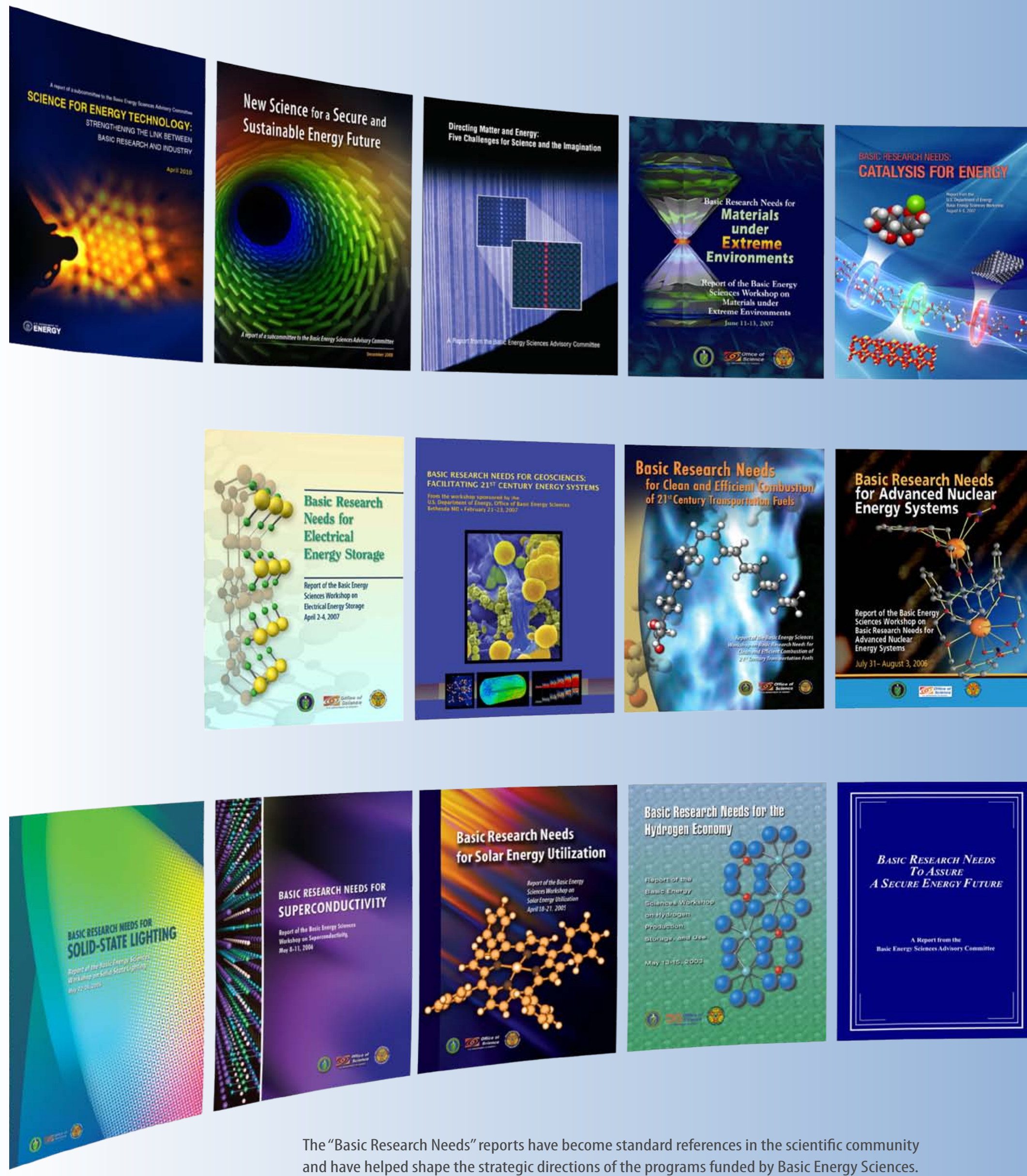

The "Basic Research Needs" reports have become standard references in the scientific community and have helped shape the strategic directions of the programs funded by Basic Energy Sciences. http://www.sc.doe.gov/bes/reports/list.html 


\section{DISCLAIMER}

This report was prepared as an account of work sponsored by an agency of the United States Government. Neither the United States government nor any agency thereof, nor any of their employees, makes any warranty, express or implied, or assumes any legal liability or responsibility for the accuracy, completeness, or usefulness of any information, apparatus, product, or process disclosed, or represents that its use would not infringe privately owned rights. Reference herein to any specific commercial product, process, or service by trade name, trademark, manufacturer, or otherwise, does not necessarily constitute or imply its endorsement, recommendation, or favoring by the United States Government or any agency thereof. The views and opinions of authors expressed herein do not necessarily state or reflect those of the United States Government or any agency thereof.

The report is available online at http://www.sc.doe.gov/bes/reports/list.html.

Publishing support services provided by Argonne National Laboratory 
